\title{
Correction to: Retrieval analysis of contemporary antioxidant polyethylene: multiple material and design changes may decrease implant performance
}

\author{
Arianna Cerquiglini ${ }^{1}$ - Johann Henckel ${ }^{1} \cdot$ Harry Hothi ${ }^{1} \cdot$ Lukas B. Moser $^{2,3}$ - Antti Eskelinen ${ }^{4}$. \\ Michael T. Hirschmann ${ }^{2,3} \cdot$ Alister J. Hart ${ }^{1}$
}

Published online: 31 August 2019

(c) European Society of Sports Traumatology, Knee Surgery, Arthroscopy (ESSKA) 2019

\section{Correction to: \\ Knee Surgery, Sports Traumatology, Arthroscopy \\ (2019) 27:2111-2119 \\ https://doi.org/10.1007/s00167-019-05387-5}

Unfortunately, Fig. 1 caption was incorrectly updated in the original publication and correct Fig. 1 version is updated here.
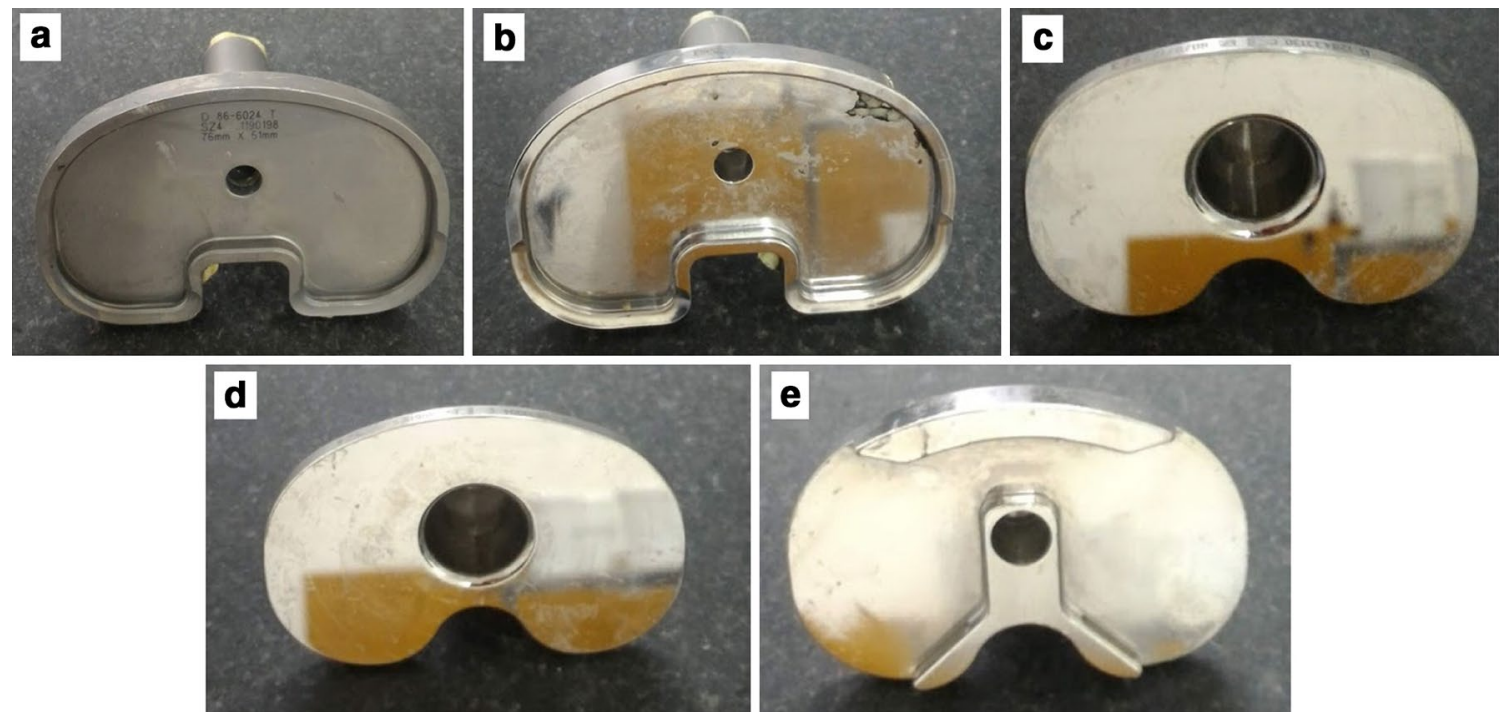

Fig. 1 Examples of two designs and relative iterations involved in the study: a Ti PFC fixed bearing, b CoCr PFC fixed bearing, $\mathbf{c}$ CoCr PFC RP, d Attune rotating bearing, e Attune fixed bearing

The original article can be found online at https://doi.org/10.1007/ s00167-019-05387-5.

Arianna Cerquiglini

arianna.cerquiglini.15@ucl.ac.uk

1 Institute of Orthopaedics and Musculoskeletal Science,

University College London, Royal National Orthopaedic

Hospital, Brockley Hill, Stanmore, Middlesex HA7 4LP, UK
Publisher's Note Springer Nature remains neutral with regard to jurisdictional claims in published maps and institutional affiliations.

2 Department of Orthopaedic Surgery and Traumatology, Kantonsspital Baselland (Bruderholz, Liestal, Laufen), Bruderholz, Switzerland

3 University of Basel, Basel, Switzerland

4 The Coxa Hospital for Joint Replacement, Tampere, Finland 